\title{
A comparative study of intravenous hydration and amnioinfusion for IUGR associated with oligohydramnios in pregnant women and fetomaternal outcome
}

\section{Garima Kumari*}

Department of Obstetrics and Gynecology, SMS Medical College and Hospital, Jaipur, Rajasthan, India

Received: 08 December 2020

Revised: 01 February 2021

Accepted: 02 February 2021

\author{
*Correspondence: \\ Dr. Garima Kumari, \\ E-mail: garimabagaria22@gmail.com
}

Copyright: ( $)$ the author(s), publisher and licensee Medip Academy. This is an open-access article distributed under the terms of the Creative Commons Attribution Non-Commercial License, which permits unrestricted non-commercial use, distribution, and reproduction in any medium, provided the original work is properly cited.

\begin{abstract}
Background: Ultrasound assessment of amniotic fluid has significant implication in obstetric care and it has become an integral and important component of pregnancy assessment.

Methods: A prospective study done in all pregnant women $(n=30)$ who had been diagnosed with oligohydromnios (with AFI $<8$ by Phelan's method) by ultrasonography will be attending in obstetric gynecology department SMS Medical College, Jaipur will be selected according to inclusion or exclusion criteria (as per sample size) after written informed consent.

Results: Higher incidence of preterm delivery in the i.v. infusion group as compared to the amino acid group and difference was significant ( $\mathrm{p}$ value $<0.05$ ). In amnioinfusion group 3 cases $(20.0 \%)$ had LSCS and in i.v. infusion group 6 cases $(40.0 \%)$ had delivered by LSCS. The distribution of delivery mode did not differ significantly across two intervention groups ( $p$ value $>0.05$ ). Significantly higher proportion of cases from amino acid group had larger birth weight and significantly higher proportion of cases from i.v. infusion group had smaller birth weight ( $p$ value $<0.001)$.

Conclusions: This study points towards the use of intravenous hydration and amnioinfusion in increasing the liquor in oligohydramnios associated with IUGR and proves useful in reducing perinatal morbidity and mortality.
\end{abstract}

Keywords: Amnioinfusion, Intravenous hydration, Oligohydramnios

\section{INTRODUCTION}

Ultrasound assessment of amniotic fluid has significant implication in obstetric care and it has become an integral and important component of pregnancy assessment. ${ }^{1,2}$ Its evaluation is vital for predicting fetal well-being as abnormalities of amniotic fluid are often associated with fetal mortality, morbidity and anomaly.,4 The importance of the amniotic fluid volume as an indicator of fetal wellbeing has been extensively documented. ${ }^{5-11}$ It reflects both mother and fetal status. ${ }^{12}$ The maintenance of appropriate amniotic fluid volume for gestational age remains an important and integral component for fetal well-being determination. ${ }^{13}$

\section{Objective}

To compare the fetal outcome of intravenous infusions versus amnioinfusion for oligohydramnios during pregnancy and to compare the efficacy of intravenous infusion drip versus amnioinfusion in increasing fetal weight and amniotic fluid. 


\section{METHODS}

\section{Study site}

This study was conducted at Department of Obstetrics and Gynecology and Surgery SMS Hospital, Jaipur, Rajasthan.

\section{Study population}

All pregnant women $(n=30)$ who had been diagnosed with oligohydromnios (with AFI $<8$ by Phelan's method) by ultrasonography attending in obstetric gynecology department SMS Medical college, Jaipur.

\section{Study design}

It was a prospective study. Sample size was 30. This study took place from April 2016 till May 2018.

\section{Calculation of sample size}

The following formula was applied for calculation of the sample size $\mathrm{n}=\frac{4 \mathrm{pq}}{\mathrm{L}^{2}}$

Where,

$\mathrm{n}=$ sample size, $\mathrm{p}=$ positive character $\mathrm{q}=1-\mathrm{p}$,

$\mathrm{L}=$ Allowable error

As incidence is $50 \%$, hence $\mathrm{p}=0.5, \mathrm{q}=0.5, \mathrm{~L}=10 \%=0.1$

$\mathrm{n}=4 \times 0.5 \times 0.5 / 0.1 \times 0.1=100$.
Thus by applying this formula minimal sample size required was 100 .

\section{Inclusion criteria}

Subjects were the women with IUGR and oligohydramnios confirmed clinicosonologically at 28-41 weeks of pregnancy, singleton pregnancy, antenatal cases between $19-40$ years

\section{Exclusion criteria:}

Severe anemia, heart disease, pre-existing or gestational diabetes maternal pulmonary disorder, premature rupture of membranes congenital malformation in baby, women who did not give consent

\section{Data collection}

According to the proforma approved by the guide and coguide which included all the details of clinical and diagnostic tests done.

\section{Data entry}

Data was entered on Microsoft excel for the convenience of transport to analysis software.

\section{Statistical methods}

In this study all the analysis will be performed by using statistical software SPSS version 10.0.

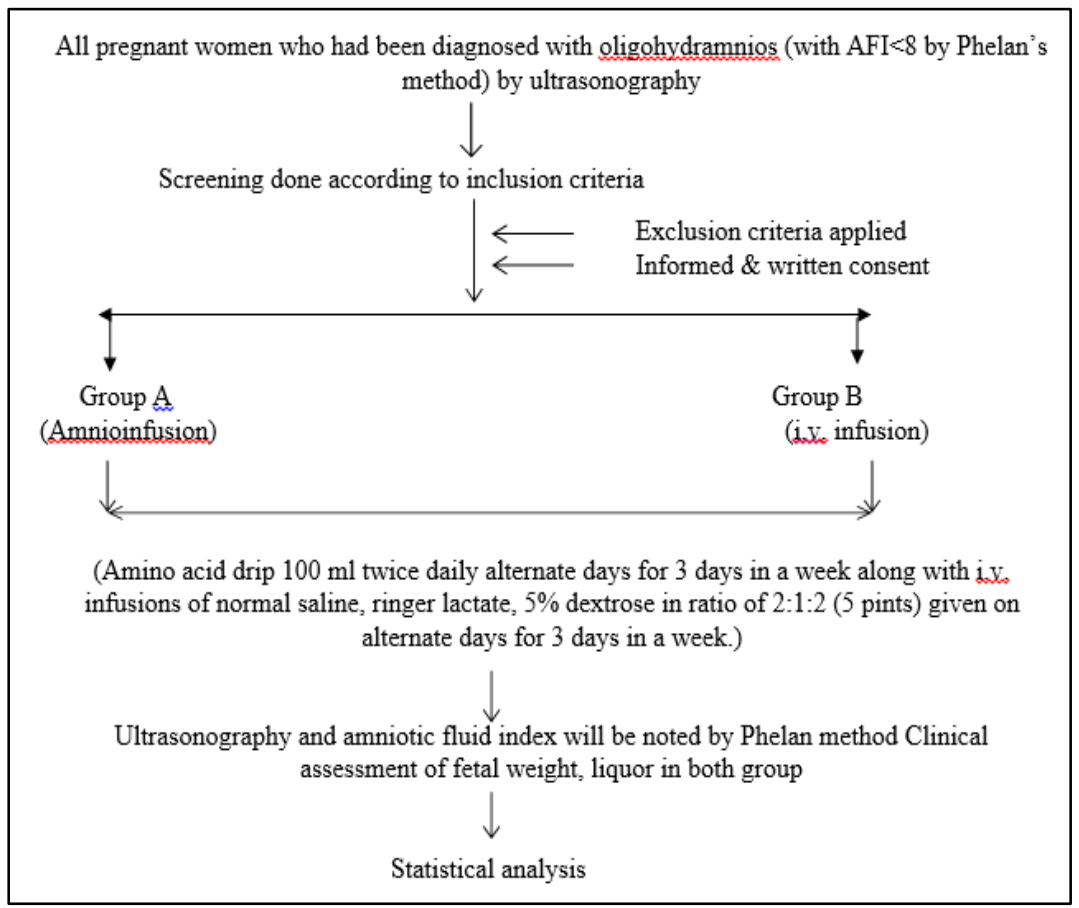

Figure 1: Methodology flow chart. 


\section{RESULTS}

The 30 cases studied, 4 cases (13.3\%), had age between 19-24 years, 12 cases $(40.0 \%)$ had age between $25-29$ years, 10 cases $(30.3 \%)$ had age between $30-35$ years, 4 cases $(13.3 \%)$ had age between $35-40$ years.

Table 1: The age distribution of the women studied $(\mathbf{n}=30)$.

\begin{tabular}{|lll|}
\hline Age group (years) & No. of cases & \% of cases \\
\hline $\mathbf{1 9 - 2 4}$ & 4 & 13.3 \\
\hline $\mathbf{2 5 - 2 9}$ & 12 & 40.0 \\
\hline $\mathbf{3 0 - 3 5}$ & 10 & 33.3 \\
\hline $\mathbf{3 5 - 4 0}$ & 4 & 13.3 \\
\hline Total & 30 & 100 \\
\hline
\end{tabular}

In amnioinfusion 1 case $(6.6 \%)$ had delivery at gestational age between 28-31 weeks, 7 cases (46.7\%) had delivery at gestational age between 32-35 weeks, 7 cases $(46.7 \%)$ had delivery at gestational age between $36-$ 40 weeks and in i.v. infusion group 6 cases $(40.0 \%)$ had delivery at gestational age between 28-31 weeks and 9 cases $(60.0 \%)$ had delivery at gestational age between 32 35 weeks.

Table 2: The distribution of gestational age at the time of delivery across two groups of intervention $(n=30)$.

\begin{tabular}{|llll|}
\hline $\begin{array}{l}\text { Gestational age } \\
\text { (weeks) }\end{array}$ & Group A & Group B & P value \\
\hline $\mathbf{2 8 - 3 1}$ & $1(6.6)$ & $6(40.0)$ & $0.004^{*}$ \\
\hline $\mathbf{3 2 - 3 5}$ & $7(46.7)$ & $9(60.0)$ & \\
\hline $\mathbf{3 6 - 4 0}$ & $7(46.7)$ & 0 & \\
\hline Total & $15(100.0)$ & $15(100.0)$ & \\
\hline
\end{tabular}

Values are $\mathrm{n}$ (\% of cases). $\mathrm{P}$ value by Chi-Square test, $\mathrm{p}$ value $<0.05$ is statistically considered significant. *p value $<0.05$.

In i.v. infusion group cases had delivery earlier than amnioinfusion group and difference was statistically significant ( $\mathrm{p}$ value $<0.05$ ).

Table 3: The distribution of maternal outcome across two groups of intervention $(n=30)$.

\begin{tabular}{|llll|}
\hline Delivery/outcome & Group A & Group B & P value \\
\hline LSCS & $3(20.0)$ & $6(40.0)$ & $0.232^{\mathrm{NS}}$ \\
\hline Normal & $12(80.0)$ & $9(60.0)$ & \\
\hline Total & $15(100.0)$ & $15(100.0)$ & \\
\hline
\end{tabular}

Values are $\mathrm{n}$ (\% of cases). $\mathrm{P}$ value by Chi-Square test, $\mathrm{p}$ value $<0.05$ is statistically considered significant. NS is statistically considered non-significant.

Of the 15 cases studied, in amnioinfusion group 3 cases (20.0\%) had LSCS and 12 cases $(80.0 \%)$ had normal vaginal delivery. Of the 15 cases in IV infusion group 6 cases $(40.0 \%)$ had delivered by LSCS and 9 cases $(60.0 \%)$ had delivered by normal vaginal delivery. The distribution of delivery mode did not differ significantly across two intervention groups ( $\mathrm{p}$ value $>0.05)$.

Table 4: The distribution of birth weight across two groups of intervention $(n=30)$.

\begin{tabular}{|llll|}
\hline Birth weight & Group A & Group B & P value \\
\hline$<\mathbf{2 5 0 0}$ & $2(13.3)$ & $11(73.3)$ & $0.001 * * *$ \\
\hline$\geq \mathbf{2 5 0 0}$ & $13(86.7)$ & $4(26.7)$ & \\
\hline Total & $15(100.0)$ & $15(100.0)$ & \\
\hline
\end{tabular}

Values are $\mathrm{n}$ (\% of cases). $\mathrm{P}$ value by Chi-square test, $\mathrm{p}$ value $<0.05$ is statistically considered significant. ${ }^{*} p$ value $<0.05$.

$* * * \mathrm{P}$ value $<0.001$ (statistically highly significant).

The 30 cases studied, in amnioinfusion group 2 cases $(13.3 \%)$ had delivered baby of birth weight $<2500 \mathrm{gm}$ and 13 cases $(86.7 \%)$ had delivered baby of birth weight $\geq 2500$ gm. In i.v. infusion group 11 cases $(73.3 \%)$ had delivered baby of birth weight $<2500 \mathrm{gm}$ and 4 cases (26.7\%) had delivered baby of birth weight $\geq 2500$. Significantly higher proportion of cases from amino acid group had larger birth weight and significantly higher proportion of cases from i.v. infusion group had smaller birth weight ( $\mathrm{p}$ value <0.001).

Higher incidence of preterm delivery in the normal saline group as compared to the amino acid group and difference was significant ( $\mathrm{p}$ value <0.05). In amnioinfusion 1 case $(6.6 \%)$ had delivery at gestational age between $28-31$ weeks, 7 cases $(46.7 \%)$ had delivery at gestational age between $32-35$ weeks, 7 cases $(46.7 \%)$ had delivery at gestational age between $36-40$ weeks and in i.v. infusion group 6 cases $(40.0 \%)$ had delivery at gestational age between $28-31$ weeks and 9 cases $(60.0 \%)$ had delivery at gestational age between $32-35$ weeks.

Of the 15 cases studied, in amnioinfusion group 3 cases (20.0\%) had LSCS and 12 cases $(80.0 \%)$ had normal vaginal delivery. Of the 15 cases in i.v. infusion group 6 cases $(40.0 \%)$ had delivered by LSCS and 9 cases $(60.0 \%)$ had delivered by normal vaginal delivery. The distribution of delivery mode did not differ significantly across two intervention groups ( $\mathrm{p}$ value $>0.05$ ).

The 30 cases studied, in amnioinfusion group 2 cases (13.3\%) had delivered baby of birth weight $<2500 \mathrm{gm}$ and 13 cases $(86.7 \%)$ had delivered baby of birth weight $\geq 2500$ gm. In i.v. infusion group 11 cases $(73.3 \%$ ) had delivered baby of birth weight $<2500 \mathrm{gm}$ and 4 cases (26.7\%) had delivered baby of birth weight $\geq 2500 \mathrm{gm}$. The distribution of birth weight differs significantly across two intervention groups ( $\mathrm{p}$ value $<0.001$ ).

Significantly higher proportion of cases from amino acid group had larger birth weight and significantly higher proportion of cases from i.v. infusion group had smaller birth weight ( $\mathrm{p}$ value $<0.001$ ). 


\section{DISCUSSION}

Oligohydramnios is a late sign of foetal malnutrition. Over the years many different medical and surgical interventions have been tried to improve the liquor in oligohydramnios. Various studies have suggested improvement of AFI by infusion of amino acids and large amounts of glucose and even $10 \%$ maltose. Maternal hydration and infusion of amino acids is a well-known therapeutic intervention to improve the placental fluid transfer. With respect to physiological principles, water transfer between mother and foetus is regulated by osmotic forces, in which electrolyte gradients determine net trans-placental water exchange.

The obstetric outcome of these patients has been detailed in table no 3 , it can be seen that $30 \%$ of the total sample size required a caesarean delivery, the main indication being fetal decelerations. This can be attributed to the fact that foetuses with oligohydramnios are likely to experience cord compression and variable decelerations. The incidence of caesarean delivery was high in normal saline group $(40 \%)$ in comparison with the amino acid infusion group (20\%). The difference was statistically not significant. The findings are consistent with the results observed by Hebbar et al, who found a caesarean section rate of around $62 \%$ in their study. ${ }^{15}$

The distribution of birth weight differs significantly across two intervention groups ( $p$ value $<0.001 \%$ ). Significantly higher proportion of cases from amino acid group had larger birth weight and significantly higher proportion of cases from normal saline group had smaller birth weight. This difference might be because of higher percentage $(40 \%)$ of women in normal saline group delivered between 28-31 weeks of gestation as compared to only one woman $(6.6 \%)$ in the amino acid group delivered in this gestation period. This was comparable with Shivumar et al in his study: the role of intravenous hydration and amino acid infusion in oligohydramnios, where amino acid drip given every alternate day in cases of oligohydramnios improved foetal weight significantly. ${ }^{16}$

Higher incidence of preterm delivery in the normal saline group as compared to the amino acid group. There was no incidence of necrotizing enterocolitis, hypoxic ischemic encephalopathy, or sepsis in any of the baby and there was no neonatal mortality. These results were also comparable to the study by Prabha et al. ${ }^{14}$

This study has several limitations and the foremost being a small sample size. To prove the point a study with large sample size needs to be done. Another limitation was the other confounding factors like subclinical infections, asymptomatic bacteriuria which lead to higher incidence of preterm delivery in the normal saline group. There should have been an equal sample size for each gestational age and the AFI group. There is continuous search for alternate suitable therapies to improve AFI in oligohydramnios.

\section{CONCLUSION}

This study points towards the use of intravenous hydration and amnioinfusion in increasing the liquor in oligohydramnios and proves useful in reducing perinatal morbidity and mortality and thus improving pregnancy outcomes, prolonging gestational age at time of delivery thereby improvement in weight gain. The amino acid therapy is more useful in patients with foetal growth restriction. Proper diet, rest, oral hydration and foetal surveillance have comparable outcomes as with intravenous infusions. Intravenous normal saline drip is cost effective as compared to the amino acid group.

Funding: No funding sources

Conflict of interest: None declared

Ethical approval: The study was approved by the Institutional Ethics Committee

\section{REFERENCES}

1. Ali HS. Assessment of amniotic fluid index in normal pregnancy at a tertiary care hospital setting. J Ayub Med Coll Abbottadad. 2009;21:149-51.

2. Igbinidu E, Akhigbe AO, Akinola RA. Sonographic evaluation of the amniotic fluid index in normal singleton pregnancies in a Nigerian population. IOSR J Dent Med Sci. 2013;6(29):e33.

3. Birang SH. Ultrasonographic assessment of normal amniotic fluid index in a group of Iranian women. Iran J Radiol. 2008;5:31-4.

4. Schrimmer DB, Moore TR. Sonographic evalution of amniotic fluid volume. Clin Obstet Gynaecol. 2002;45:1026-38.

5. Chamberlain PF, Manning FA, Morrison I, Harman CR, Lange IR. Ultrasound evaluation of amniotic fluid. The relationship of increase amniotic fluid volume to perinatal outcome. Am J Obstet Gynaecol. 1984;150:250-4.

6. Shmoys SM, Sivkin M, Dery C, Monheit AG, Baker DA. Amniotic fluid index: An appropriate predictor of perinatal outcome. Am J Perinatol. 1990;7:266-70.

7. Sarno AP, Ahn MO, Brar HS, Phelan JP, Platt LD. Intrapartum doppler velocimetry, amniotic fluid volume and fetal heart rate as predictors of subsequent fetal distress. Am J Obstet Gynaecol. 1989;161:1508-11.

8. Sarno AP, Ahn MO, Phelan JP. (1990) Intrapartum amniotic fluid volume at term: Association of ruptured membranes, oligohydramnios and increased fetal risk. J Reprod Med. 1990;35:719-22.

9. Carlson DE, Platt LD, Medearis AL, Horenstein J. Qualifiable polyhydramnios: diagnosis and management. Obstet Gynaecol. 1990;75:989-93.

10. Hill LM, Breckle R, Thomas ML, Fries JK. Polyhydramnios: ultrasonically detected prevalence 
and neonatal outcome. Obstet Gynaecol. 1987;69:21-5.

11. Brace RA, Wolf EJ. Normal amniotic fluid volume changes throughout pregnancy. Am J Obstet Gynaecol. 1989;161:382-8.

12. Hinh ND, Ladinsky JL. Amniotic fluid index measurements in normal pregnancy after 28 gestational weeks. Int $\mathbf{J}$ Gynaecol Obstet. 2005;91:132-6.

13. Pripaz S, Khalek N, Fuchs KM, Simpson LL. Maximal amniotic fluid index as a prognostic factor in pregnancies complicated by polyhydramnios. Ultrasound Obstet Gynaecol. 2012;39:648-53.

14. Prabha S, Vivekanand A, Sarojini A, Sethi P. The role of amino acid infusion in isolated Oligohydramnios. Perspect Med Res. 2015;3:1-5.
15. Hebbar S, Rai L, Adiga P. Maternal hydration and Larginine supplementation improves liquor volume in patients with decreased liquor and prolongs pregnancy. Med J Dr DY Patil Univ. 2014;7(4):429.

16. Shivkumar PV, Tayade SA, Kumar P, Tayade AT, Bagde ND, Bagde MN. The role of intravenous hydration and amino infusion in intrauterine growth restriction and oligohydramnios. Int J Biol Med Res. 2011;2:1078-83.

Cite this article as: Kumari G. A comparative study of intravenous hydration and amnioinfusion for IUGR associated with oligohydramnios in pregnant women and fetomaternal outcome. Int J Reprod Contracept Obstet Gynecol 2021;10:955-9. 